\title{
A Case of Turner's Syndrome Complicated with Desmoid Tumor of the Transverse Colon
}

\author{
NAOFUMI ERIGUCHI, SHIGEAKI AOYAGI, KOJI OKUDA, MASAO HARA, TSUYOSHI TAMAE, \\ NAOMITSU KANAZAWA, HISASHI NAKAMURA, SATOSHI FURUKAWA \\ AND KEI FUJIKI
}

Department of Surgery, Kurume University School of Medicine, Kurume 830-0011, Japan

\begin{abstract}
Summary: The association of Turner's syndrome and endometrial carcinoma has been previously established, but has never been described in conjunction with a desmoid tumor of the colon. A case is described of a colonic desmoid tumor developing in a 38-year-old female with Turner's syndrome. The association has not been previously reported. In this report, we describe a 38-yearold woman who has Turner's syndrome with a colonic desmoid and review the literature.
\end{abstract}

Key words Turner's syndrome, desmoid tumor, gastrointestinal tumor

\section{INTRODUCTION}

Turner's syndrome is a result of a variety of abnormalities of the $\mathrm{X}$ chromosome. There are several reports that the risk of malignancy, both gonadal and nongonadal, is increased in patients with such chromosomal defects. The desmoid tumor is a virtually non-metastasizing tumor composed of fibrous tissue, with no apparent histologic features of malignancy but with significant potential for local invasiveness and recurrence. Presented here is a patient with Turner's syndrome who developed a desmoid tumor of the colon at 38 years of age.

\section{CASE REPORT}

A 38-year-old female patient was admitted to our hospital because of a palpable mass in the upper abdomen since that had been present for three years. She had neither abdominal pain nor gastrointestinal complaints. She had never had a menstrual period. Clinical examinations revealed a short girl who was $129.6 \mathrm{~cm}$ tall with scoliosis. The patient's head had no deformities, but the neck was short and mildly webbed with a low hairline in the back. Her chest was broad and shield-like with lateralization and hypoplasia of the nipples. The external genitalia were female in character, but immature, with no growth of axillary or pubic hair. Chromosome analysis was not performed in our hospital because she had been diagnosed with Turner's syndrome by an outside gynecologist. She had been treated for a dislocation of the right hip joint and a horseshoe kidney. There was a huge abdominal mass in her abdomen which she had palpated herself 3 years previously. It was hard and was not fixed. The abdominal tumor has become larger in size without any symptoms. Laboratory data revealed no abnormal findings; serum cortisol, adrenocorticotropic hormone, thyroxine levels were within normal range. Serum alpha fetoprotein was also at a normal level.

Abdominal computed tomography (CT) showed a large mass lesion which revealed a slightly lower attenuation than muscle tissue (Fig. 1a). Barium enema of the large intestine revealed an oppressive finding of the transverse colon (Fig. 1b).

The clinical diagnosis was Turner's syndrome with an abdominal tumor possibly arising from the transverse colon.

At laparotomy, there was a $15 \times 12 \times 11 \mathrm{~cm}$ tumor arising from the transversal colon. Her genital organs such as the uterus and ovary were very small in size 
a

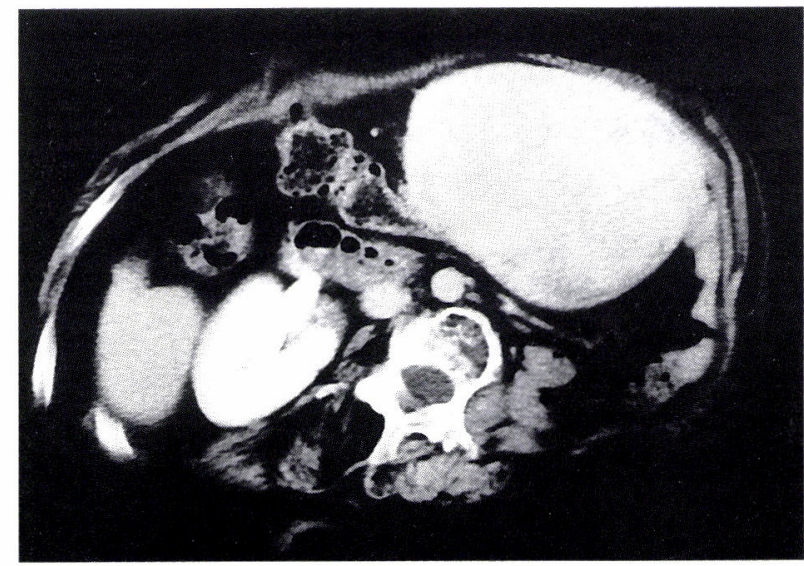

b

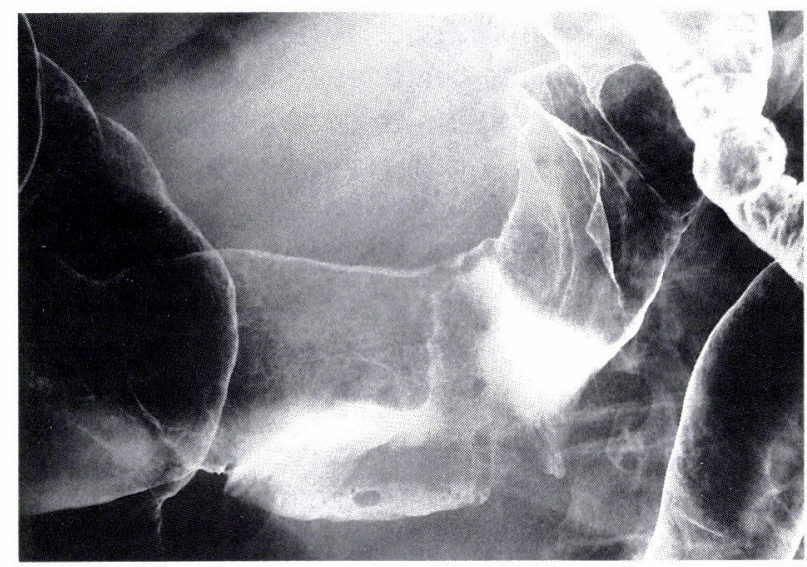

Fig. 1. a: Abdominal computed tomography showed a large mass lesion in the abdominal cavity. b: Barium enema of the large intestine revealed an oppressive finding of the transverse colon. a

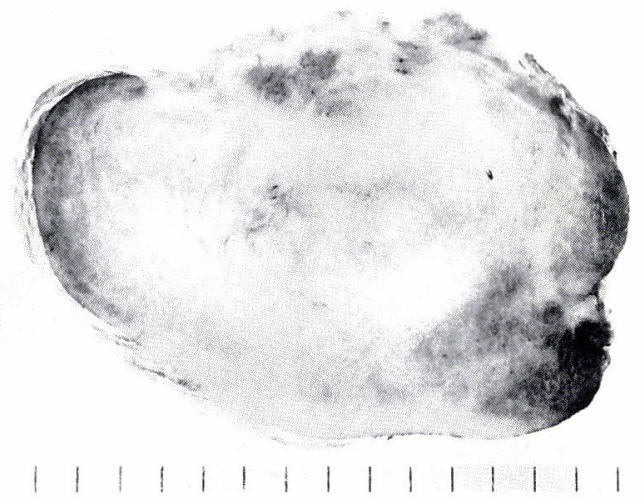

b

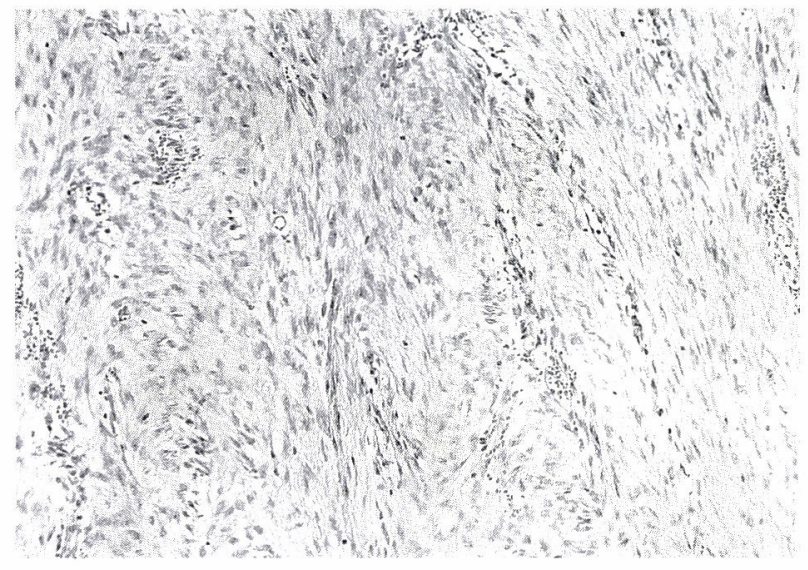

Fig. 2. a: Cut surface of the resected specimen showed a large solid tumor with no areas of necrosis or bleeding. b: Histopathological finding was desmoid tumor of the colon. The tumor cells are composed of a proliferation of elongated slender spindle cells with minimal atypia and bundles of collagen between them. (H.\& E. × 50)

\section{DISCUSSION}

Turner's syndrome is the result of a variety of abnormalities of the $X$ chromosome, varying from complete absence to a 45 , XO karyotype to minimal alterations such as mosaicism. The typical features in a patient with Turner's syndrome are short stature, infantilism, streak gonads with several associated congenital malformations. The etiology of the chromosomal aberration could be due to nondisjunction of the sex chromosome or deletion of varying portions of the $\mathrm{X}$ or $\mathrm{Y}$ chromosome.

The structural abnormalities of the internal organs include coactation of the aorta, pulmonary stenosis, renal abnormalities, such as the horseshoe kidney in our case, rotation of the kidney, duplication of the 
TABLE 1.

Reported cases of Turner's syndrome associated with gastrointestinal neoplasm

\begin{tabular}{|c|c|c|c|c|c|c|}
\hline No & Author & Year & Age & Organs & Histologic type & Reference \\
\hline 1 & Sternlieb & '54 & 38 & Colon & Adenocarcinoma & N Y J Med 54:1663-1665 \\
\hline 2 & Engel & '65 & 44 & Colon & Adenocarcinoma & Medicine 44:135-164 \\
\hline 3 & Wertelecki & 70 & 13 & Cecum & Carcinoid & Cancer 26:485-488 \\
\hline 4 & Wertelecki & '70 & 38 & Sigma & Adenocarcinoma & \\
\hline 5 & Wertelecki & 70 & 44 & Sigma & Adenocarcinoma & \\
\hline 6 & Wertelecki & '70 & 38 & Sigma & Adenocarcinoma & \\
\hline 7 & Herrera-Ornelas & '84 & 43 & Colon & Adenocarcinoma & J Surg Oncol 27:251-254 \\
\hline 8 & Cheng & '93 & 49 & Colon & Adenocarcinoma & J Formos Med Assoc 92:580-582 \\
\hline 9 & Present case & '99 & 39 & Colon & Desmoid tumor & \\
\hline 10 & Pich & '37 & 49 & Stomach & Adenocarcinoma & Beitr Pathol Anat 98:218-263 \\
\hline 11 & Engel & '65 & 63 & Stomach & Adenocarcinoma & Medicine 44:135-164 \\
\hline 12 & Wertelecki & '70 & 63 & Stomach & Adenocarcinoma & Cancer 26:458-488 \\
\hline 13 & Wertelecki & '70 & 49 & Stomach & Adenocarcinoma & \\
\hline 14 & Siegler & '75 & 34 & Stomach & Adenocarcinoma & Postgrad Med J 51:411-412 \\
\hline 15 & Cayla & '84 & 64 & Stomach & Adenocarcinoma & Rev Rhum 51:281-282 \\
\hline 16 & Yata & '94 & 64 & Stomach & Leiomyosarcoma & Jpn J Gastroenterol 91:1328-1332 \\
\hline
\end{tabular}

renal pelvis and ureter, and rarely gastro-intestinal telangiectasia and Hirschsprung's disease [1,2]. As for the high percentage of tumors among cases of Turner's syndrome, it is known that dysgenetic gonads give rise to neoplastic change [3]. This is related to the presence of $\mathrm{Y}$ chromosomal components [3-5]. The most common tumor which arises from the dysgenetic gonad is gonadoblastoma [5]. According to the report on a multi-hospital survey of 289 cases by Wertelcki et al. [6], 8 patients were found to have nongonadal tumors. Thus, gastro-intestinal tumors associated with Turner's syndrome are relatively rare, especially in the form of colonic desmoids (Table 1). There were 16 cases of gastro-intestinal tumor, including our case. Seven of them were colonic cancer and only one case was carcinoid tumor of the cecum. Six of 7 gastric malignant tumors were gastric cancer, and leiomyosarcoma occurred in 1 patient. Patients ranged in age from 13 to 64 years (mean, 45 years).

Intraabdominal desmoid tumors are infrequently encountered in surgical practice and, when seen, are most often genetically determined tumors associated with Gardner's syndrome or familial adenomatous polyposis syndrome (FAP).

Trauma and endocrine and genetic factors seem to be implicated in the pathogenesis of desmoid tumors; however, the exact pathogenesis is unclear [7].
The mortality associated with desmoid tumors was reported to be approximately $11 \%$ of all deaths in patients with FAP and $31 \%$ of deaths after colectomy, making it the second most common cause of death once colorectal cancer is excluded [8]. Therefore, alternative treatment strategies, including radiation therapy [9-11], nonsteroidal antiinflammatory agents [12], antiestrogen compounds [13-17], and cytotoxic chemotherapy $[18,19]$ have been employed.

Since metastasis almost never occurs, aggressive surgical removal of the tumors is the first treatment of choice. A surgical approach aiming at clear margins is presently the best treatment option. When this cannot be accomplished without severe disfigurement or functional impairment, partial resection is an acceptable alternative. Adjuvant strategies, preoperatively and/or after partial resection, should be considered in the context of an actively growing tumor with potential for mortality or significant morbidity.

ACKNOWLEDGMENTS: The authors would like to express their deepest thanks to Dr. K. Shimamatsu (Department of Pathology, Kurume University School of Medicine) and Prof. H. Hashimoto (First Department of Pathology, Faculty of Medicine, Kyushu University) for histopathological advice and suggestions. 


\section{REFERENCES}

1. Conte FA, and Grumbach MM. Syndrome of gonadal dysgenesis and its variants. In: Endocrinology, ed. DeGroot LJ, WB Saunders, Philadelphia, Vol. 3, pp 1817-1822, 1989.

2. Crumbach MM, and Conte FA. The syndrome of gonadal dysgenesis: Turner's syndrome and its variants. In: Williams Textbook of Endocrinology 8th ed., ed. Wilson JD and Foster DW, WB Saunders, Philadelphia, pp 884901, 1992.

3. Teter J, and Boczkowski K. Occurrence of tumors in dysgenetic gonads. Cancer 1967; 20:1301-1310.

4. Schellas HF. Malignant potential of the dysgenetic gonad. Obstet and Gynecol 1974; 44:298-309.

5. Scully RE. Gonadblastoma. A review of 74 cases. Cancer 1970; 25:1340-1356.

6. Wertelecki W, Fraumeni JF Jr, and Mulvihill JJ. Nongonadal neoplasia in Turner's syndrome. Cancer 1970; 26:485-488.

7. Reitamo JJ, Scheinin TM, and Hayry P. The desmoid syndrome. New aspects in the cause, pathogenesis and treatment of desmoid tumors. Am J Surg 1986; 151:230237.

8. Aravantis ML, Jagelman DG, Fazio VW, Lavery IC, and McGannon E. Mortality in patients with familial adenomatous polyposis. Dis Colon Rectum 1990; 33:639-642.

9. Acker JC, Bossen EH, and Halperin EC. The management of desmoid tumors. Int J Radiat Oncol Biol Phys
1993; 26:851-858.

10. Goy BW, Lee SP, Fu YS, Selch MT, and Eilber F. Treatment results of unresected or partially resected desmoid tumors. Am J Clin Oncol 1998; 21:584-590.

11. Ballo MT, Zagars GK, and Pollack A. Radiation therapy in the management of desmoid tumors. Int J Dariat Oncol Biol Phys 1998; 42:1007-1014.

12. Waddell W, Gerner R, and Reich M. NSAIDs and tamoxifen for desmoid tumours and carcinoma of the stomach. J Surg Oncol 1983; 22:197-211.

13. Lanari A. Effect of progesterone on desmoid tumors. $\mathrm{N}$ Engl J Med 1983; 309:1523.

14. Sportiello DJ, and Hoogerland DL. A recurrent pelvic desmoid tumor successfully treated with tamoxifen. Cancer 1991; 67:1443-1446.

15. Wilcken N, and Tattersal MHN. Endocrine therapy for desmoid tumors. Cancer 1991; 68:1384-1388.

16. Bauernhofer T, Stoger H, Schmid M, Smola M, GurtlLackner B et al. Sequential treatment of recurrent mesenteric desmoid tumor. Cancer 1996; 77:1061-1065.

17. Maroy B. Desmoid tumor sensitive to tamoxifen. Presse Med 1997; 26:1520-1522.

18. Patel SR, Evans HL, and Benjamin RS. Combination chemotherapy in adult desmoid tumors. Cancer 1993; 72:3244-3247.

19. Kitamura A, Kanagawa $T$, Yamada S, and Kawai $T$. Effective chemotherapy for abdominal desmoid tumor in a patient with Gardner's syndrome. Dis Colon Rectum 1991; 34:822-826. 